\title{
Study of cognitive functions in major idiopathic interstitial pneumonias
}

\author{
Mohamed W. Zakaria', Reem I. El-Korashy', Mostafa O. Shaheen², Samah Selim ${ }^{1 *}$ (D) and Kwashi J. Amum ${ }^{3}$
}

\begin{abstract}
Background: Cognitive dysfunction in idiopathic interstitial pneumonia (IIP) is an important clinical co-morbidity that is associated with impaired lung function. The aim of the work is to assess cognitive function in major IIP and to find out the relation between cognitive dysfunction and the oxygenation parameters.

Results: Fifty individuals were involved in the study; 30 patients with major IIP and 20 healthy individuals. Patients with IIP had significantly lower mini mental state examination (MMSE) score compared to the control group ( $P<$ 0.001). Wechsler Deterioration Index (WDI) revealed that 33.3\% $(n=10)$ of the patients with IIP had sure cognitive impairment and $26.6 \%(n=8)$ had ongoing cognitive deterioration. Patients with idiopathic pulmonary fibrosis (IPF) had lower cognitive function than other IIP.

Conclusion: There is an impairment of cognitive function in patients with major IIP, particularly in IPF, as measured by WDI and MMSE. Further large studies are needed to assess the possible predictors of cognitive impairment and their effects on the patients' outcome.
\end{abstract}

Keywords: Cognition, Idiopathic interstitial pneumonia, MMSE, WDI

\section{Background}

Idiopathic interstitial pneumonias are interstitial lung diseases of unknown aetiology that have similar clinical and radiological features. They differ primarily by the histological patterns on lung biopsy that is characterized by variable degrees of inflammation and fibrosis [1].

Major idiopathic interstitial pneumonias $\left(\right.$ IIP $\left._{S}\right)$ include the entities of idiopathic pulmonary fibrosis (IPF), nonspecific interstitial pneumonia (NSIP), cryptogenic organizing pneumonia (COP), acute interstitial pneumonia (AIP), respiratory bronchiolitis-associated interstitial lung disease (RB-ILD), and desquamative interstitial pneumonia (DIP) [2].

$\mathrm{IIP}_{\mathrm{S}}$ have been associated with several co-morbidities, including gastro-esophageal reflux disease, coronary artery disease, pulmonary hypertension, and venous thromboembolic disease. In addition to that, cognitive

\footnotetext{
* Correspondence: samah.selim@ymail.com

'Department of Chest Diseases, Faculty of Medicine, Cairo University, Cairo, Egypt

Full list of author information is available at the end of the article
}

dysfunction is considered an important clinical comorbidity which is associated with impaired lung functions that suggest a systemic disease [3]. It is well known also that cerebral oxygen desaturation is significantly associated with decrease in cognitive functions [4].

Assessments of cognitive functions include wide range of capabilities, including attention, memory, problem solving, and intellectual functions. It is a process of detection of a patient cognitive strength and weakness via qualitative and quantitative approach [5].

The aim of the study was to assess the cognitive functions in patients with major IIP. $_{S}$. The secondry goal was to find out the relation between cognitive function and the oxygenation parameters.

\section{Methods \\ A prospective case control study that was conducted at the Chest Department, Kasr Al-Ainy Hospital, Cairo University, in collaboration with the Psychiatry Depart- ment during the period between February 2016 and April 2017. It was carried out on 50 individuals; 30}


patients with major idiopathic interstitial pneumonias who were diagnosed based on multidisciplinary review of the clinical, radiological, and pathological data according to the guidelines of the international consensus statement produced as a collaborative effort from the American Thoracic Society and European Respiratory Society Guidelines 201 3[2], and 20 healthy individuals.

This human study was performed in accordance with the Declaration of Helsinki and was approved by the ethical committee of the Faculty of Medicine, Cairo University. All adult participants provided written informed consent to participate in the study.

All patients were subjected to the following:

1. Thorough history taking and clinical examination including age, sex, smoking status, and modified Medical Research Council scale (mMRC) for dyspnea.

2. Six minute walk test (6MWT): Every patient was instructed to wear his/her comfortable footwear. The patient's usual medication should be continued and the patient should not have exercised vigorously within $2 \mathrm{~h}$ before the beginning of the test. The objective of this test is to measure the distance walked as far as possible for $6 \mathrm{~min}$ [6].

3. Spirometry: It was performed using master screen Jager-D 97204 Hochberg Germany. Measurement of the forced expiratory volume in the first second (FEV1\% predicted), forced vital capacity (FVC\% predicted), FEV1/FVC \%, forced expiratory flow (FEF25-75\% predicted) were obtained. The presence of an FEV1/FVC $>0.70$ together with FVC < $80 \%$ predicated confirm the presence of restriction. The severity of restriction was determined according to the results of FVC as follows [7]: mild restriction: FVC $60-80 \%$, moderate: FVC $40-59 \%$, and severe restriction: FVC less than $40 \%$.

4. High-resolution computed tomography (HRCT) of the chest.

5. Echocardiography: Assessment of pulmonary artery systolic pressure.

6. Measurement of arterial blood gases (ABG): One $\mathrm{ml}$ of arterial blood was obtained from the radial artery in a heparinized needle and then taken immediately to a blood gas analyzer (pHOx plus $\mathrm{C}$ ) to assess the $\mathrm{PH}, \mathrm{PaO}_{2}, \mathrm{PaCO}_{2}$, and $\mathrm{SaO}_{2}$. Calculation of alveolar-arterial oxygen pressure difference $\left(\mathrm{PA}-\mathrm{a} \mathrm{O}_{2}\right.$ ) was carried out.

The two groups; the patients, and the control group were subjected to Cognitive assessment tests, which included the following:

1. Wechsler Adult Intelligent Scale (WAIS).
2. Mini Mental State Examination (MMSE) test.

\section{Cognitive function assessment Wechsler Adult Intelligent Scale (WAIS)}

Wechsler adult intelligent scale (WAIS) is an intelligent IQ test that measures the intelligence and cognitive function in adults and older adolescents (Fig. 1) [8].

\section{WAIS score}

The WAIS is an IQ test that is given by psychologists and measures global intellectual function, it includes both verbal and non-verbal components. The WAIS report subtests score are labeled; extremely low for 4 and below, borderline for $5-6$, low average for 7 , average for $8-11$, high average for $12-13$, superior for $14-15$, and very superior for 16 and up.

The average score for all test and subtest is 100; thus, a score above 100 is above average and below 100 is below average [9]. The examinee is given three basic scores: verbal IQ, performance IQ, and full IQ.

\section{Analyzing WAIS score}

The first step in analyzing score is to look at the WAIS composite score and the IQ, where the average score is 100. Anything from 90 to 109 is considered average. Score from 110 to 119 is considered high average, from 120 to 129 is superior, and from 130 and up is very superior. On the other end of the spectrum, from 80 to 89 is considered below average, 70 to 79 is borderline and from 69 and below is extremely low. Once the scores are interpreted, the next step is to check for strength and weakness of each test and subtest.

\section{Calculation of Wechsler Deterioration Index (WDI)}

This is a ratio between two groups of subtests:

The first group of subsets includes four subtests that are little affected with age:

- Comprehension.

- Picture completion.

- Information (or vocabulary).

- Object assembly.

The second group of subsets includes those that show more rapid decline with age:

- Arithmetic.

- Digit span.

- Block design.

- Digit symbol.

A ratio derived from the two groups of subtest; provides the deterioration index or estimate of mental 


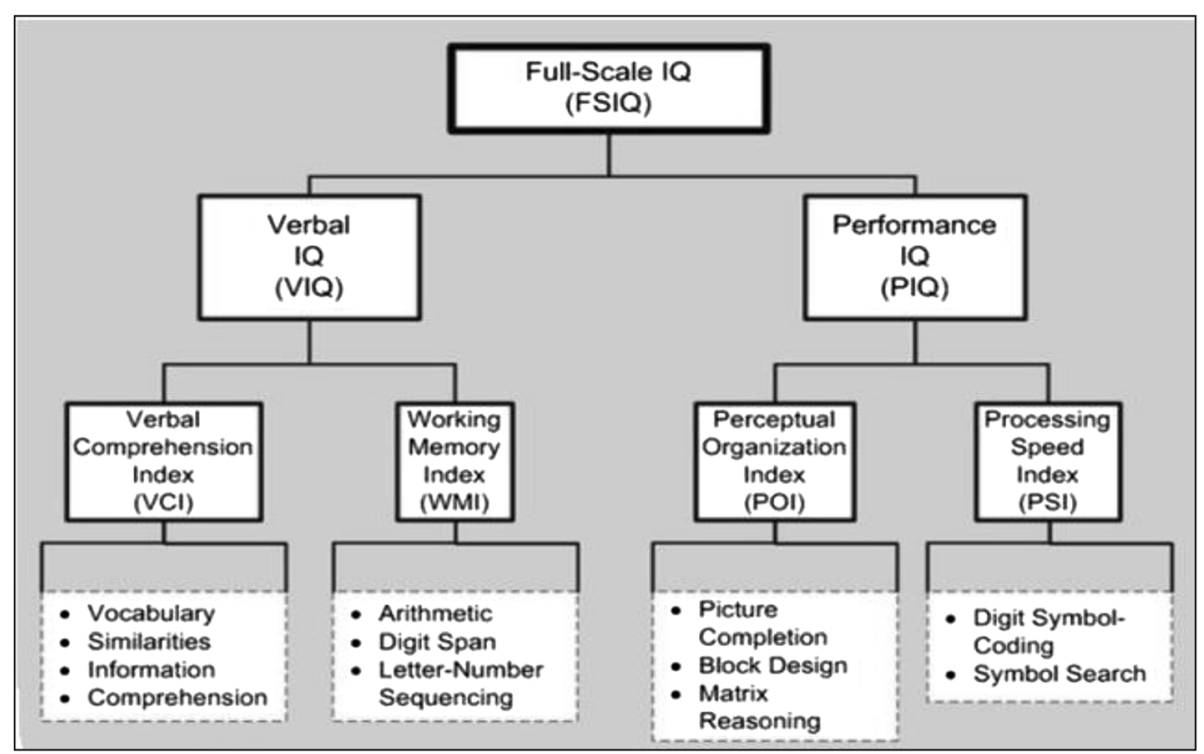

Fig. 1 WAIS major components

decline. This index can be compared for the average or normal decline with age.

Significant deviation from the normal pattern for a specific age group is then considered indicative of deterioration [10].

The interpretation of the test is as the following:

- < 10: no deterioration.

- 10-< 18: deterioration may be present.

- $\geq 18$ : Sure deterioration.

\section{Mini-Mental State Examination (MMSE)}

Administration of MMSE takes between 5 and $10 \mathrm{~min}$; it consists of 11 questions that measure 5 areas of cognitive function which include registration, attention and calculation, recall, and language, ability to follow simple command, and orientation. The maximum score is 30 , a score of 23 or lower is indicative of cognitive impairment [11].

A copy of mini-mental state examination questionnaire is attached at the end.

\section{Statistical analysis}

Sample size was calculated and data were coded and entered using the statistical package SPSS version 25. Data was summarized using mean and standard deviation for quantitative variables and frequencies (number of cases) and relative frequencies (percentages) for categorical variables. Comparison between both groups was done using independent sample $t$ test or Mann-Whitney rank sum test or chi-square when appropriate. Correlation between quantitative variables was done using Pearson correlation coefficient, $P$ values less than 0.05 were considered as statistically significant.

\section{Results}

\section{Patients' characteristics}

In total, 30 patients with a diagnosis of IIP and 20 healthy individuals were involved in the study. Patients' characteristics are shown in Table 1.

The median age of the patients with IIP was 44 years whereas the median age of the control group was 41.5. Also, there was no statistical difference between both groups as regards the sex and smoking habit.

Idiopathic pulmonary fibrosis represented 50\% $(n=$ 15) of the involved patients followed by non-specific interstitial pneumonia $(40 \%, n=12)$ and most of the patients had severe restrictive function. Advanced grade of dyspnea was present in seventeen patients.

\section{Oxygenation parameters}

The mean arterial oxygen pressure $\left(\mathrm{P}_{\mathrm{a}} \mathrm{O}_{2}\right)$ was 46.53 $\mathrm{mmHg}$, the mean alveolar-arterial oxygen pressure (PAa $\mathrm{O}_{2}$ ) difference was $51.07 \mathrm{mmHg}$, and room air arterial oxygen saturation $\left(\mathrm{SaO}_{2}\right)$ was $82 \%$.

\section{Cognitive function of the studied groups}

The patients' group was significantly associated with mental state disability $(P=0.03)$, also they had significantly lower MMSE score in comparison to the control group $(P<0.001)$ (Table 2$)$.

The verbal IQ of the patients' groups was not significantly lower than the control one, $(P=0.07)$, even though some of its subscales (similarities, information, vocabulary, and comprehension) were significantly lower 
Table 1 The clinical characteristic of the study population

\begin{tabular}{|c|c|c|c|}
\hline Parameter & $\mathrm{IIP}_{\mathrm{S}}$ group $(N=30)$ & Control group $(N=20)$ & $P$ value \\
\hline Age (years) & $44(40-57)$ & $41.5(39.25-55.25)$ & $0.38^{\wedge \wedge}$ \\
\hline Sex (female) & $17(56.67 \%)$ & $10(50 \%)$ & $0.82^{\#}$ \\
\hline Smoking (no) & $21(70 \%)$ & $10(50 \%)$ & $0.25^{\#}$ \\
\hline Pulmonary hypertension & $14(46.67 \%)$ & & \\
\hline \multicolumn{4}{|l|}{$\mathrm{IIP}_{\mathrm{S}}$ types: } \\
\hline $\begin{array}{l}\text { DIP } \\
\text { IPF } \\
\text { NSIP } \\
\text { RB-ILD }\end{array}$ & $\begin{array}{l}2(6.67) \\
15(50 \%) \\
12(40 \%) \\
1(3.33 \%)\end{array}$ & & \\
\hline \multicolumn{4}{|l|}{ Severity of restriction: } \\
\hline $\begin{array}{l}\text { Mild } \\
\text { Moderate } \\
\text { Severe }\end{array}$ & $\begin{array}{l}3(10 \%) \\
10(33.33 \%) \\
17(56.67 \%)\end{array}$ & & \\
\hline \multicolumn{4}{|l|}{ Dyspnea score (mMRC): } \\
\hline $\begin{array}{l}1 \\
2 \\
3 \\
4\end{array}$ & $\begin{array}{l}4(13.33 \%) \\
7(23.33 \%) \\
9(30) \\
10(33.33)\end{array}$ & & \\
\hline 6MWD(meter) & $148.67 \pm 116.49$ & & \\
\hline
\end{tabular}

Abbreviations: IIPS idiopathic interstitial pneumonias, DIP desquamative interstitial pneumonia, IPF idiopathic pulmonary fibrosis, NSIP non-specific interstitial pneumonia, RB-ILD respiratory bronchiolitis-associated interstitial lung disease, 6MWD 6 minute walk distance

Numerical data normally distributed represented as mean \pm SD and data not normally distributed represented as median (Q1-Q3), categorical data as number (\%) $\wedge \wedge$ Mann-Whitney rank sum test

${ }^{\#}$ Chi-square; $N$ number, significant $P$ value $<0.05$

with $P=0.003,0.007,0.01$, and 0.002 , respectively. In the same way, the performance IQ was not significantly decreased in the patients in comparison with the control subjects, and in spite of that, some of its subscales were significantly lower in the patients' group; block design, matrix design, and digit symbol $(P=0.002,0.024$, and $0.03)$, respectively. At the end, the total WAIS IQ score was not lower enough to be significant in patients' group $(P=0.14)$ (Table 3$)$.

According to the Wechsler Deterioration Index, it was found that $33.3 \%(n=10)$ of the patients with IIP had sure cognitive impairment and 26.6\% $(n=8)$ had ongoing cognitive deterioration.

\section{Correlation between cognitive functions and the oxygenation parameters}

There was statistical significant positive correlation between $\mathrm{PaO}_{2}$ and performance IQ while a non-significant positive correlation between performance IQ and $\mathrm{SaO}_{2}$, and negative correlation with $\mathrm{PA}-\mathrm{aO}_{2}$ difference (Table 4).

\section{Comparison between IPF and other IIP}

Table 5 shows that MMSE score was significantly lower in IPF patients, also the cognitive disability significantly affecting IPF patients $[(P=0.01$ and 0.05$)$, respectively]. Besides, the verbal IQ was significantly affected $(P=$ 0.05).

\section{Discussion}

In the current study, the UIP/IPF accounts for almost $50 \%(n=15)$ of the all cases followed by NSIP which accounts for $40 \%(n=12)$, while all other patterns accounts for almost 10\% (DIP 6.6\% \&RB-ILD 3.3\%) (Table 1). This matches with Raghu and co-workers [12] who named IPF as the most common form of $\operatorname{IIP}_{S}$, and Kim and colleagues [13] who stated that UIP/IPF ranges between 47 and $64 \%$ from the whole populations in

Table 2 Mini Mental State Examination of the studied groups

\begin{tabular}{|c|c|c|c|c|c|}
\hline \multirow{2}{*}{$\begin{array}{l}\text { Parameter } \\
\text { MMSE (number of affected patients) }\end{array}$} & \multicolumn{2}{|c|}{ IIP $_{S}$ group } & \multicolumn{2}{|c|}{ Control group } & \multirow{2}{*}{$\frac{P \text { value }}{0.03^{\#}}$} \\
\hline & 10 & $33.33 \%$ & 1 & $5 \%$ & \\
\hline MMSE score & 25 & $(22-28)$ & 29.5 & $(28-30)$ & $<0.001^{\wedge \wedge}$ \\
\hline
\end{tabular}

Numerical not normally distributed data represented as median (Q1-Q3), categorical data as number (\%)

$\wedge \wedge$ Mann-Whitney rank sum test

${ }^{\#}$ Chi-square; significant $P$ value $<0.05$ 
Table 3 Wechsler Adult Intelligent Scale (WAIS) in both groups

\begin{tabular}{llllll}
\hline Parameter & \multicolumn{2}{l}{ IIP group } & \multicolumn{2}{l}{ Control group } & $\boldsymbol{P}$ value \\
\hline Total IQ & 86.17 & 11.42 & 90.6 & 8.62 & 0.14 \\
Verbal IQ & 85.93 & 12.39 & 92.4 & 11.95 & 0.07 \\
Arithmetic & 5 & $(3-7)$ & 6 & $(5.25-8)$ & 0.1 \\
Digit span & 7 & $(4-8.25)$ & 7 & $(7-8)$ & $0.3^{\wedge}$ \\
Similarities & 7.37 & 1.92 & 9 & 1.622 & $0.003^{\wedge}$ \\
Information & 5 & $(5-7)$ & 7 & $(6-7)$ & $0.007^{\wedge}$ \\
Vocabulary & 6.5 & $(5-8)$ & 8 & $7-9$ & 0.01 \\
Comprehension & 9.03 & 2.98 & 11.75 & 2.92 & $0.002^{\wedge}$ \\
Performance IQ & 91.3 & 12.73 & 92.85 & 10.21 & 0.65 \\
Block design & 5.73 & 1.70 & 7.25 & 1.52 & $0.002^{\wedge}$ \\
Matrix design & 7 & $(5-8)$ & 7 & $(7-9)$ & $0.024^{\wedge}$ \\
Visual puzzle & 7.83 & 2.42 & 9.10 & 2.36 & $0.07^{\wedge}$ \\
Picture completion & 6.5 & $(5-7)$ & 7 & $(7-8)$ & $0.08^{\wedge \wedge}$ \\
Digit symbol & 6.63 & 1.65 & 7.85 & 2.30 & $0.03^{\wedge}$ \\
\hline
\end{tabular}

Normal numerical data represented as mean (SD) and abnormal one as

median (Q1-Q3), categorical data as number (\%)

$\wedge$ Independent sample $t$ test

$\wedge \wedge$ Mann-Whitney rank sum test, significant $P$ value $<0.05$

different studies, and RB-ILD/DIP ranges between 10 and $17 \%$. While Belloli and co-workers [14] stated that idiopathic NSIP incidence is almost half the incidence of IPF.

There was a female predominance in IIP patients (female:male ratio $=1.3: 1$ ), while in Lee et al. 2011 [15], there was a reverse in the ratio female:male $=1: 1.58$.

It has been stated that UIP/IPF is more prevalent in males and mortality is higher too [16] that was attributed to more deterioration in exercise desaturation over time in comparison to females and a suggestion of uncharacterized sex related effect [17]. However, in our study, the female:male ratio in this pathological entity was 11:4.

In the USA, from 1992 to 2003, the age adjusted mortality rate increased $28.4 \%$ in men and $41.13 \%$ in women,

Table 4 Correlation of oxygenation parameters, with MMSE and WAIS (total $I Q$, verbal $I Q$, and performance $I Q$ ) ${ }^{*}$

\begin{tabular}{llllll}
\hline & & MMSE & Total IQ & Verbal IQ & Performance IQ \\
\hline $\mathrm{PaO}_{2}$, & $\boldsymbol{r}$ & 0.207 & 0.266 & 0.116 & 0.396 \\
& $\boldsymbol{P}$ value & 0.273 & 0.156 & 0.542 & 0.030 \\
$\mathrm{SaO}_{2}$ & $\boldsymbol{r}$ & 0.185 & 0.140 & 0.010 & 0.311 \\
& $\boldsymbol{P}$ value & 0.327 & 0.460 & 0.959 & 0.095 \\
$\mathrm{PA}_{-\mathrm{aO}} \mathbf{2}$ & $\boldsymbol{r}$ & $-0.250-$ & -0.276 & -0.207 & -0.315 \\
& $\boldsymbol{P}$ value & 0.182 & 0.140 & 0.273 & 0.090 \\
\hline
\end{tabular}

Abbreviations: $\mathrm{PaO}_{2}$ arterial oxygen tension, $\mathrm{SaO}_{2}$ arterial oxygen saturation, $P A-a O_{2}$ alveolar-arterial oxygen pressure difference, MMSE Mini Mental State Examination, WAIS Wechsler Adult Intelligent Score

"Pearson correlation, the sign before $(r)$ represent the direction of correlation, while $P$ represents the significant of correlation, significant $P$ value $<0.05$ with significant increase all years in both sexes especially females [18].

Almost all patients were presented with moderate to severe restriction pattern by spirometry (Table 1). A picture which by itself may reflect the presence of concomitant cognitive dysfunction as was mentioned by Lutsey and co-workers [19], who studied 14,184 participants with spirometry and found that midlife lung disease and reduced lung functions were associated with modestly increase odds of mild cognitive dysfunction. Almost 33\% of the patients had dyspnea grade 4 , a very distressing symptom associated with increased rate of depression and decrease functional status [20]. This late presentation is proved by presence of respiratory failure type 1 , where the mean $\mathrm{PaO}_{2}$ was $46.5+11.85 \mathrm{mmHg}$, and arterial oxygen saturation was $82 \%$. The mean alveolararterial oxygen pressure difference was $51.07+14.63$ $\mathrm{mmHg}$. It was suggested that hypoxia may cause gradual prefrontal deoxygenation which leads to alternating short term memory and executive functions at earlier stages followed by cognitive dysfunctions at later stages [21].

Almost half of the patients (46.67\%) presented with echo-cardiographic picture suggestive of pulmonary hypertension as a complication of the disease. Despite that Anderson and co-workers, 2012 [22] stated that the incidence of pulmonary hypertension was $14 \%$. Subsequent studies have increased this percentage to be between 32 and 50\% [23].

As regards IPF, Collum and colleagues [24] highlighted the difficulty in defining the prevalence of pulmonary hypertension due to differences in the underlying disease severity, diagnostic modality, and patient population.

The late presentation of the patients was seen reflected on the exercise capacity of the patients, which showed 6-MWT distance $148.67 \pm 116.49$ meters. This late presentation also affects the intellectual and cognitive functions of the patients. The importance of this test lies in being an independent predictor of mortality in IPF patients, where the presence of $6 \mathrm{MWD}<250$ meters carries two fold increase in the risk of mortality as stated by $\mathrm{du}$ Bois and co-workers [25].

Interstitial lung disease (ILD) is a chronic condition with distressing dyspnea, progressive worsening of exercise tolerance, and decreased life expectancy. Many researchers studied depression and anxiety in ILDs being prevalent [20]. However, very few researchers tackled the cognitive impairment. Soliman and colleagues [26] studied cognitive auditory functions in IIP $_{S}$ patients and proved the presence of cognitive dysfunction in these patients.

In this study, cognitive function was assessed using Wechsler Adult Intelligent Scale (WAIS). There was a significant difference between both groups in terms of verbal 
Table 5 Comparison between IPF patients and other IIPS patients

\begin{tabular}{llllll}
\hline Parameter & IPF $(\boldsymbol{N}=\mathbf{1 5})$ & & Other IIPS $(\boldsymbol{N}=\mathbf{1 5})$ & \multicolumn{2}{c}{} \\
\hline MMSE score & 23.66 & 2.82 & 26.4 & 2.80 & $0.01^{\wedge}$ \\
MMSE (number of affected patients) & 8 & 53.33 & 2 & 13.33 & $(89-94)$ \\
Total IQ & 82 & $(27-90)$ & 91 & $9.05^{\#}$ \\
Verbal IQ & 81.66 & 13.91 & 90.2 & 9.06 & 0.05 \\
Performance IQ & 88.60 & 14.05 & 94.00 & 11.07 & 0.25 \\
\hline
\end{tabular}

Abbreviations: IPF idiopathic pulmonary fibrosis, IIP idiopathic interstitial pneumonias, MMSE Mini Mental State Examination, $N$ number Normal numerical data represented as mean (SD) and abnormal one as median (Q1-Q3), categorical data as number (\%)

^Independent sample $t$ test

${ }^{\#}$ Chi-square; significant $P$ value $<0.05$

IQ subclasses (similarities, information, vocabulary, and comprehension) and some of items of the performance IQ subclasses (block design, matrix design, and digit symbol) (Table 3). Also, when performing MMSE, there was a statistical significant difference between both groups also (Table 2), which proves the presence of lower level of cognitive function in patients with idiopathic interstitial pneumonias in comparison with the healthy control group.

Furthermore, we calculated the deterioration index which is a pattern of subtest score on WAIS. It was attributed to David Wechsler, (Wechsler Deterioration Index (WDI)).

WDI is viewed as a suggestive of decline from the baseline function [27]. It was found that IIP had evident effect on $33.3 \%$ of cases and the process was ongoing in $26.6 \%$ of the cases which proves the presence of deterioration in general cognitive status of patients with IIP $_{S}$.

Bors and colleagues [28] studied cognitive function in IPF patients using five neurophysiological tests and concluded that there was significant affection suggesting inferior performance on tasks requiring speed divided attention and memory. The outcome has shown that participants with severe IPF had worse cognitive function than mild IPF or control subjects.

When classifying the patients' group into IPF and other IIP $\mathrm{S}_{\mathrm{S}}$ group; the IPF patients showed significant decrease of the verbal IQ $(P=0.05)$. On the other hand, the performance IQ was not significantly decreased in IPF patients in comparison with other IIPs patients (Table 5). At the end, the total WAIS IQ score was not significantly lower enough in IPF patients in comparison with other IIPs $(P=0.06)$. These findings reflect that verbal concept formation, knowledge, as well as visual intelligence and perceptual organization were affected.

Up till now, no study was done to compare cognitive disability between IPF and other IIPs types. However, the difference could be attributed to the common prevalence of IPF, compared to other types of IIPs. IPF also advances more rapidly in some individuals and may slowly progress in others [4].

It is worth to mention that the correlation between both WAIS with its subclasses and MMSE with the oxygenation parameters showed positive significant correlation between the $\mathrm{PaO}_{2}$ and the performance subscale of WAIS, and positive non-significant correlation with $\mathrm{SaO}_{2}$, and this carry a hope for performance improvement with improvement of oxygenation.

\section{Conclusion}

There is an impairment of cognitive function in patients with major IIP, particularly in IPF, as measured by WDI and MMSE. Further large studies are needed to assess the possible predictors of cognitive impairment and their effects on the patients' outcome.

\section{Supplementary Information}

The online version contains supplementary material available at https://doi. org/10.1186/s43168-020-00046-7.

Additional file 1: Table S1. Mini mental state examination.

\section{Abbreviations}

IIP: Idiopathic interstitial pneumonia; WAIS: Wechsler Adult Intelligent Scale; MMSE: Mini Mental State Examination; WDI: Wechsler Deterioration Index; IPF: Idiopathic pulmonary fibrosis; NSIP: Non-specific interstitial pneumonia; COP: Cryptogenic organizing pneumonia; AIP: Acute interstitial pneumonia; RB-ILD: Respiratory bronchiolitis-associated interstitial lung disease;

DIP: Desquamative interstitial pneumonia; mMRC: Modified Medical Research Council scale; 6-MWT: Six minute walk test; FEV1: Forced expiratory volume in the first second; FVC: Forced vital capacity; FEF: Forced expiratory flow; HRCT: High-resolution computed tomography; ABG: Arterial blood gases; $\mathrm{PaO}_{2}$ : Arterial oxygen pressure; $\mathrm{PaCO}_{2}$ : Arterial carbon dioxide pressure; $\mathrm{SaO}_{2}$ : Arterial oxygen saturation; $\mathrm{PA}-\mathrm{aO}_{2}$ : Alveolar-arterial oxygen pressure difference; UIP: Usual interstitial pneumonia; ILD: Interstitial lung disease

\section{Acknowledgements}

All authors are thankful to Mrs. Sara El Saied, the clinical psychologist who helped in the performance and analysis of the cognitive function tests.

\section{Authors' contributions}

Concept of the study: MZ, RK, MS, and SS. Data collection: KA. Data analysis: MZ, RK, MS, SS, and KA. Writing the original draft: RK, SS, and KA. All authors participated in reviewing and editing the final paper. The author(s) read and approved the final manuscript.

\section{Funding}

Not applicable.

Availability of data and materials Not applicable. 


\section{Ethics approval and consent to participate}

The ethical committee of the Faculty of Medicine, Cairo University, approved the study (the committee's reference number is not available) and a written informed consent was obtained from each participant.

\section{Consent for publication}

Not applicable

\section{Competing interests}

Not applicable.

\section{Author details}

'Department of Chest Diseases, Faculty of Medicine, Cairo University, Cairo, Egypt. ${ }^{2}$ Psychiatry Department, Faculty of Medicine, Cairo University, Cairo,

Egypt. ${ }^{3}$ Faculty of Medicine, JUBA University, Juba, Sudan.

Received: 11 June 2020 Accepted: 17 November 2020

Published online: 30 November 2020

\section{References}

1. Travis WD, King TE, Bateman ED, Lynch DA, Capron F, Center D et al (2002) American thoracic society/European respiratory society international multidisciplinary consensus classification of the idiopathic interstitial pneumonias. Am J Respir Crit Care Med 165(2):277-304

2. Travis WD, Costabel U, Hansell DM, King TE Jr, Lynch DA, Nicholson AG et al (2013) An official American Thoracic Society/European Respiratory Society statement: update of the international multidisciplinary classification of the idiopathic interstitial pneumonias. Am J Respir Crit Care Med 188(6):733-748

3. Sharp C, Adamali HI, Millar AB, Dodd JW (2016) Cognitive function in idiopathic pulmonary fibrosis. Thorax 71:A237

4. Caminati A, Harari S (2010) IPF: New insight in diagnosis and prognosis. Respir Med 104(1):s2-s10

5. Nordlund A, Påhlsson L, Holmberg C, Lind K, Wallin A (2011) The Cognitive Assessment Battery (CAB): A rapid test of cognitive domains. Int Psychogeriatr 23(7):1144-1151. https://doi.org/10.1017/S1041610210002334

6. American Thoracic Society (2002) ATS statement: Guidelines for the six minute walk test. Am J Respir Crit Care Med 166(1):111-117

7. Pellegrino R, Viegi G, Brusasco V, Crapo RO, Burgos F, Casaburi R et al (2005) Interpretative strategies for lung function tests. Eur Respir J 26(5):948-968

8. Wechsler Adult Intelligent Scale, fourth edition, Now available from Pearson. (Press release): Pearson 2008; 08-28. Retrieved, 2012-03-20.

9. Wechsler D, Coalson DL, Raiford SE (2008) WAIS-IV Technical and Interpretive Manual. Pearson, San Antonia

10. Gluckman M. Clinical psychology: The study of personality and behavior 2017 https://doi.org/10.4324/9781315081038.

11. Folstein MF, Folstein SE, McHugh PR (1975) Mini Mental State; a practica method for grading the cognitive state of patients for clinician. J Psychiatr Res 12:189-198

12. Raghu G, Weyccker D, Edelsberg J, Bradford WZ, Oster G (2006) Incidence and prevalence of idiopathic pulmonary fibrosis. Am J Respir Crit Care Med 174:810-816

13. Kim KK, Kugler MC, Wolters PJ, Robillard S, Galvez MG, Brunwell AN et al (2006) Alveolar epithelial cell mesenchymal transition develops in vivo during pulmonary fibrosis and is regulated by extra cellular matrix. Proc Nat Acad Sci U S A 103(35):13180-13185

14. Belloli EA, Beckford R, Hadley R, Kevin R, Flaherty KR (2016) Idiopathic nonspecific interstitial pneumonia. Respirology 21(2):259-268

15. Lee JS, Ryu JH, Elicker BM, Lydell CP, Jones KD, Wolters PJ et al (2011) Gastro esophageal reflux therapy is associated with longer survival in patients with idiopathic pulmonary fibrosis. Am J Respir Crit Care Med 184: 1390-1394

16. Natsuizaka M, Chiba H, Kuronuma K, Otsuka M, Kudo K, Mori M et al (2014) Epidemiologic survey of Japanese patients with idiopathic pulmonary fibrosis and investigation of ethnic differences. Am J Respir Crit Care Med 190(7):773-779

17. Han MK, Murray S, Fell CD, Falherty KR, Toews GB, Myers J et al (2008) Sex differences in physiological progression of idiopathic pulmonary fibrosis. Eur Respir J 31:1183-1188

18. Olson AL, Swirgris JJ, Lezotte DC, Norris JM, Wilson CG, Brown KK (2007) Incidence and mortality from pulmonary fibrosis increased in the United States from 1992 to 2003. Am J Respir Crit Care Med 176(3):277-284
19. Lutsey PL, Chen N, Mirabell MC, Lakshiminra K, Knopman DS, Vossel KA et al (2019) Impaired lung function, lung disease and risk of incidence dementia. Am J Respir Crit Care Med 199(11):1385-1396

20. Ryerson CJ, Arean PA, Berkeley J, Carrier-Kohlman VL, Pantilat SZ, Landefeld CS et al (2012) Depression is a common and chronic comorbidity in patients with interstitial lung disease. Respirology 17(3):525-532

21. Subudhi AW, Bourdillon V, Bucher J, Davic C, Elliot JE, Eutermoster M et al (2014) Alltitude Omics: the integrative physiology of human acclimatization to hypobaric hypoxia and its retention upon renascent. PLoS One 9(3):e. 92191. https://doi.org/10.1371/journalpone.0092191

22. Anderson CU, Mellemkjaer S, Hilberg O, Nielsen-Kudsk JE, Simonsen U, Bendstrup E (2012) Pulmonary hypertension in interstitial lung disease; Prevalence, prognosis and 6 minute walk test. Respir Med 106(6):875-882

23. Shorr AF, Wainright L, Cors CS, Lettieri CJ, Nathan SD (2007) Pulmonary hypertension in patients with pulmonary fibrosis awaiting lung transplant. Eur Respir J 30(4):715-721

24. Collum SD, Aminoe-Guerra J, Gruz-Solbes AS, Hernandez AM, Hammadu K, Guha A et al (2017) Pulmonary hypertension associated with idiopathic pulmonary fibrosis: current and future perspectives. Can Respir J 2017: 143035012 pages. https://doi.org/10.1155/2017/1430350

25. du Bois RM, Albera C, Brandford WZ, Costable U, Leff A, Paul W et al (2014) Six Minute Walk distance is an independent predictor of mortality in patients with idiopathic pulmonary fibrosis. Eur Respir J 43(5):1421-1429

26. Soliman YMA, Elkorashy RI, Ghamry GA, E Hedayet. Cognitive auditory dysfunction in Idiopathic Interstitial Pneumonitis. 2012. https://doi.org/1 0.1164/ajrccm-conference.2012.185.1 MeetingAbstracts.A4461.

27. Corsini RJ, Fassett KK (1952) The validity of Wechsler's Mental Deterioration Index. J Consult Psychol 16(6):462-468

28. Bors M, Tomic R, Perlman DM, Kim HJ, Whelan TP (2015) Cognitive function in Idiopathic Pulmonary Fibrosis. Chron Respir Dis 12(4):365-372

\section{Publisher's Note}

Springer Nature remains neutral with regard to jurisdictional claims in published maps and institutional affiliations.

\section{Submit your manuscript to a SpringerOpen ${ }^{\circ}$ journal and benefit from:}

- Convenient online submission

- Rigorous peer review

- Open access: articles freely available online

- High visibility within the field

Retaining the copyright to your article

Submit your next manuscript at $>$ springeropen.com 